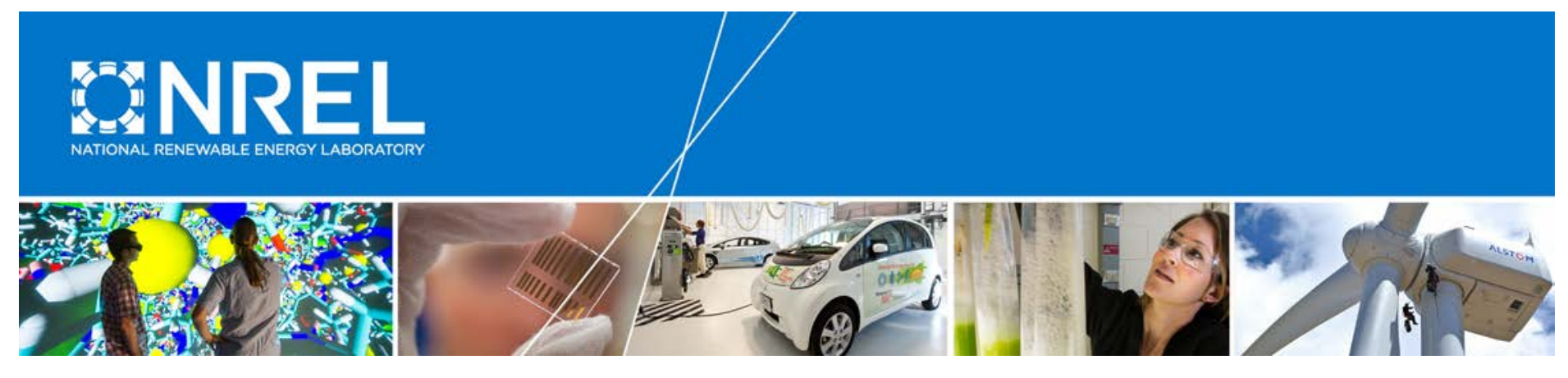

\title{
Degradation Characterization of Thermal Interface Greases
}

\section{Preprint}

Douglas DeVoto, Joshua Major, and Paul Paret National Renewable Energy Laboratory

Gregory S. Blackman, Arnold Wong, and Jeffery S. Meth

DuPont Experimental Station

Presented at the Intersociety Conference on Thermal and Thermomechanical Phenomena in Electronic Systems Orlando, Florida

May 30 - June 2, 2017

NREL is a national laboratory of the U.S. Department of Energy Office of Energy Efficiency \& Renewable Energy Operated by the Alliance for Sustainable Energy, LLC

This report is available at no cost from the National Renewable Energy Laboratory (NREL) at www.nrel.gov/publications.

Conference Paper

NREL/CP-5400-68014

August 2017

Contract No. DE-AC36-08GO28308 


\section{NOTICE}

The submitted manuscript has been offered by an employee of the Alliance for Sustainable Energy, LLC (Alliance), a contractor of the US Government under Contract No. DE-AC36-08GO28308. Accordingly, the US Government and Alliance retain a nonexclusive royalty-free license to publish or reproduce the published form of this contribution, or allow others to do so, for US Government purposes.

This report was prepared as an account of work sponsored by an agency of the United States government. Neither the United States government nor any agency thereof, nor any of their employees, makes any warranty, express or implied, or assumes any legal liability or responsibility for the accuracy, completeness, or usefulness of any information, apparatus, product, or process disclosed, or represents that its use would not infringe privately owned rights. Reference herein to any specific commercial product, process, or service by trade name, trademark, manufacturer, or otherwise does not necessarily constitute or imply its endorsement, recommendation, or favoring by the United States government or any agency thereof. The views and opinions of authors expressed herein do not necessarily state or reflect those of the United States government or any agency thereof.

This report is available at no cost from the National Renewable Energy Laboratory (NREL) at www.nrel.gov/publications.

Available electronically at SciTech Connect http:/www.osti.gov/scitech

Available for a processing fee to U.S. Department of Energy and its contractors, in paper, from:

U.S. Department of Energy

Office of Scientific and Technical Information

P.O. Box 62

Oak Ridge, TN 37831-0062

OSTI http://www.osti.gov

Phone: 865.576.8401

Fax: 865.576.5728

Email: reports@osti.gov

Available for sale to the public, in paper, from:

U.S. Department of Commerce

National Technical Information Service

5301 Shawnee Road

Alexandria, VA 22312

NTIS http://www.ntis.gov

Phone: 800.553 .6847 or 703.605 .6000

Fax: 703.605.6900

Email: orders@ntis.gov 


\title{
Degradation Characterization of Thermal Interface Greases
}

\author{
D. DeVoto, J. Major, P. Paret \\ National Renewable Energy Laboratory \\ 15013 Denver West Parkway \\ Golden, CO 80401-3305 \\ Email: douglas.devoto@nrel.gov \\ G.S. Blackman, A. Wong, J.S. Meth \\ DuPont Experimental Station \\ Wilmington, DE 19803
}

\begin{abstract}
Thermal interface materials (TIMs) are used in power electronics packaging to minimize thermal resistance between the heat generating component and the heat sink. Thermal greases are one such class of TIMs. The conformability and thin bond line thickness (BLT) of these TIMs can potentially provide low thermal resistance throughout the operation lifetime of a component. However, their performance degrades over time due to pump-out and dry-out during thermal and power cycling. The reliability performance of greases through operational cycling needs to be quantified to develop new materials with superior properties.
\end{abstract}

NREL, in collaboration with DuPont, has performed thermal and reliability characterization of several commercially-available thermal greases. Initial bulk and contact thermal resistance of grease samples were measured, and then the thermal degradation that occurred due to pumpout and dry-out during temperature cycling was monitored. The thermal resistances of five different grease materials were evaluated using NREL's steady-state thermal resistance tester based on the ASTM test method D5470. Greases were then applied, utilizing a $2.5 \mathrm{~cm} \times 2.5 \mathrm{~cm}$ stencil, between invar and aluminum plates to compare the thermomechanical performance of the materials in a representative test fixture. Scanning Acoustic microscopy, thermal, and compositional analyses were performed periodically during thermal cycling from $-40^{\circ} \mathrm{C}$ to $125^{\circ} \mathrm{C}$. Completion of this characterization has allowed for a comprehensive evaluation of thermal greases both for their initial bulk and contact thermal performance, as well as their degradation mechanisms under accelerated thermal cycling conditions.

KEY WORDS: thermal interface materials, thermal resistance, thermal conductivity, steady-state technique, greases, silicone, non-silicone

\section{NOMENCLATURE}

$A \quad$ metering block cross-sectional area, $\mathrm{m}^{2}$

$B L T \quad$ bond line thickness

$k$ thermal conductivity of metering block, W/m-K

NREL National Renewable Energy Laboratory

$\mathrm{R}$ thermal resistance, $\mathrm{mm}^{2}-\mathrm{K} / \mathrm{W}$

$T$ temperature, ${ }^{\circ} \mathrm{C}$

TIM thermal interface material

$\Delta x_{1} \quad$ distance between $T_{1}$ and $T_{2}$ or $T_{3}$ and $T_{4}, \mathrm{~m}$

$\Delta x_{2} \quad$ distance between $T_{2}$ or $T_{3}$ and sample interface, $\mathrm{m}$

\section{Greek symbols}

$\lambda$ thermal conductivity, $\mathrm{W} / \mathrm{m}-\mathrm{K}$

\section{Subscripts}

avg average

$\mathrm{s}$ top top of the interface material

$\mathrm{s}$ bot bottom of the interface material

top top metering block

bot bottom metering block

$1,2,3,4$ locations of temperature measurement in the metering blocks

\section{INTRODUCTION}

Modern power electronics packages continue to increase in power density in each subsequent generation of devices. With these advances, thermal management of the package becomes more challenging. A successful cooling solution must address the needs of a chip that operates at higher power levels and higher heat fluxes. Innovative thermal management solutions are needed to ensure that future package architectures can operate at their maximum performance potential by minimizing the overall thermal resistance from the junction of the device to the cooling medium. TIMs are a critical solution for minimizing the contact resistance between the power electronics module and the cold plate assembly. It is difficult to assess the thermal performance and reliability of TIMs in their final packaged configuration, therefore several test standards and modeling approaches have been created to quantify their bulk and contact thermal resistances [1]. Transient thermal characterization tests of TIMs can achieve high measurement throughput, but also require knowledge of a material's density and specific heat [2]. Furthermore, it is difficult to measure the effect of pressure on BLT in most transient technique fixtures. ASTM test method D5470-12 [3] is the gold standard for measuring bulk thermal conductivity, but there are significant complications when measuring grease-based TIMs, many of which will be addressed in this paper.

An improved steady-state thermal resistance method (ASTM 5470-12) has been used for many years at NREL for the characterization of thermal greases, bonded interface materials, motor laminations, and other materials [4-6]. A key outcome for any measurement technique is the accuracy and reproducibility of the results. Caution is necessary when using the technique because of the potential of significant errors due to RTD placement, machine tolerances, BLT measurement, 
and the influence of contact resistance [7]. Keeping this in mind, a number of authors have successfully constructed test apparatuses that exceed the requirements of the ASTM D5470 standard by employing new measurement methods or improved fixture designs. Chen et al. used a specimen area of $12.7 \times 12.7 \mathrm{~mm}$ to minimize planarity issues and a ChargeCoupled Device (CCD) camera to measure BLT [8]. Khounsary et al. completed steady-state tests under vacuum to characterize the contact resistance of metal foils [9]. Culham et al. also completed tests under a vacuum and compared the benefits of various BLT measurement techniques, including direct measurement, linear variable differential transformers (LVDTs), and lasers [10]. In replacing thermocouples or RTDs with heat flux and temperature measuring chips, Székely et al. were able to capture measurements closer to the test sample [11]. Their use of a symmetrical design, replacing heater cartridges and a cold plate with Peltier cells, allowed for the capability of reversing the heat flow through the sample. Kempers et al. quantified the uncertainty of each measured quantity within their D5470 test setup and used thermistors for thermal measurement [12]. Xu and Fisher used the technique to quantify the thermal contact conductance enhancement by the use of carbon nanotube (CNT) arrays [13]. AboRas et al. used a silicon chip both as a heat source and temperature sensor to more closely replicate an actual package [14]. Modifications to the ASTM D5470 standard at NREL will be discussed to further improve the accuracy and repeatability of this steady-state test method. Best practices for the use of glass spheres as spacers, BLT measurement techniques, and RTD calibration are reviewed, and a largearea fixture for simulating grease degradation from pump-out and dry-out during temperature cycling is discussed.

\section{MATERIALS AND PROCEDURE}

\section{TIM Stand Description}

Five commercially available thermal greases, both silicone and non-silicone, were tested in the ASTM D5470 steadystate tester developed at NREL. Identities of the greases are anonymized during this study. The basic configuration of the apparatus is shown in Fig. 1.

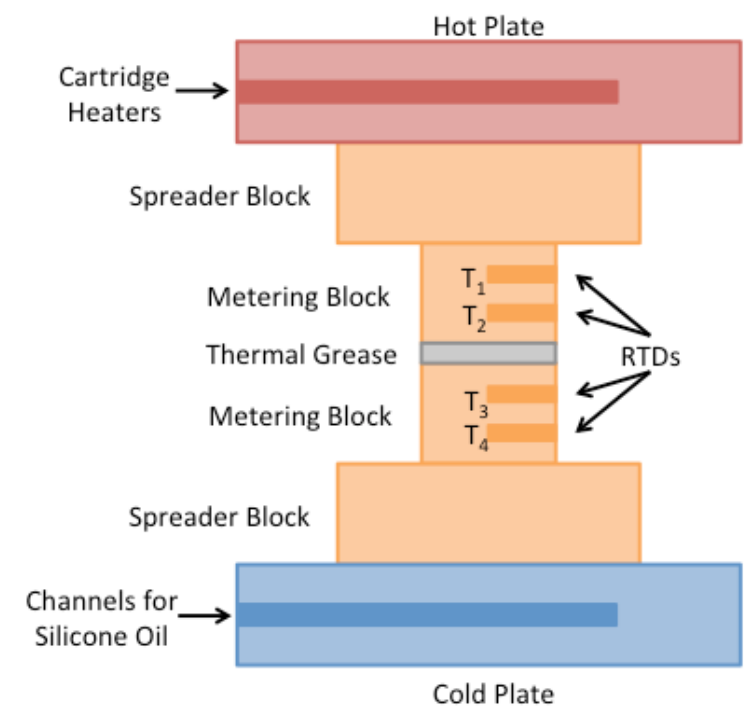

Fig. 1 Steady-state thermal resistance testing apparatus
Two heater cartridges are embedded into an aluminum hot plate while silicone oil is circulated through an aluminum cold plate. Four RTDs are embedded in metering blocks that have the TIM material applied between them. The opposing surfaces are highly polished to reduce variability in thickness measurements. Glass spheres of a known diameter representative of the desired BLT, ranging from $25 \mu \mathrm{m}$ to 250 $\mu \mathrm{m}$, are also applied between the metering blocks to ensure a consistent and known thickness of the test material.

The top and bottom heat fluxes through the metering blocks are first calculated through the following two equations:

$$
\begin{aligned}
& Q_{t o p}=k \cdot A\left(T_{1}-T_{2}\right) / \Delta x_{1} \\
& Q_{b o t}=k \cdot A\left(T_{3}-T_{4}\right) / \Delta x_{1}
\end{aligned}
$$

where:

$Q_{\text {top }}=$ top metering block heat flux calculation in $\mathrm{W}$

$Q_{\text {bot }}=$ bottom metering block heat flux calculation in $\mathrm{W}$

$k=$ thermal conductivity of metering block

$A \quad=$ metering block cross-sectional area

$T_{1,2,3,4}=$ temperature measurements from hot plate side (1) to cold plate side (4)

$\Delta x_{1} \quad=$ distance between $T_{1}$ and $T_{2}$ or $T_{3}$ and $T_{4}$

The average heat flux is determined from the top-side and bottom-side metering blocks by:

$$
Q_{\text {avg }}=\left(Q_{\text {top }}+Q_{\text {bot }}\right) / 2
$$

The temperature at the interface between the top metering block and the top-side of the interface material is determined by:

$$
T_{\text {s top }}=T_{2}-\Delta x_{2} \cdot\left(\left(T_{1}-T_{2}\right) / \Delta x_{1}\right)
$$

where:

$T_{\text {s top }}=$ calculated temperature of the test sample's top surface

$\Delta x_{2}=$ distance between $T_{2}$ or $T_{3}$ and sample interface

The temperature of the interface between the bottom metering block and the bottom-side of the interface material is calculated in a similar manner:

$$
T_{s \text { bot }}=T_{3}+\Delta x_{2} \cdot\left(\left(T_{3}-T_{4}\right) / \Delta x_{1}\right)
$$

The total thermal resistance is calculated by:

$$
R=\left(\left(T_{\text {stop }}-T_{\text {s bot }}\right) \cdot A\right) / Q_{\text {avg }}
$$

\section{Glass Sphere Diameter Characterization}

Manufacturer data sheets provide a range in particle sizes, but for precise control of the BLT, the glass sphere spacers must be carefully characterized. A method to quickly measure the diameters of a large population of glass spheres was developed. 


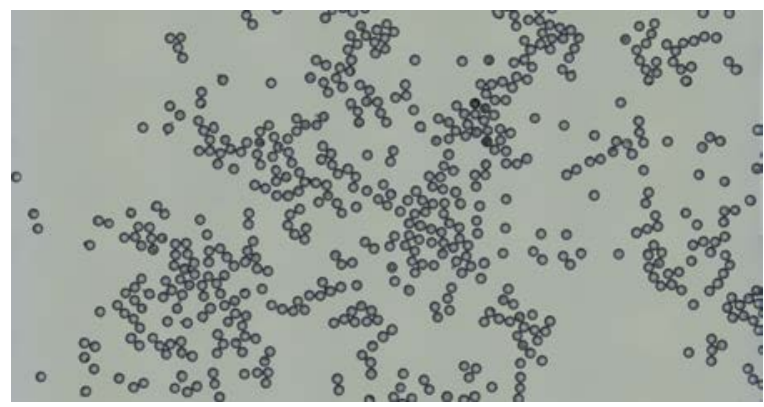

Fig. 2 Glass sphere distribution under a microscope

Several hundred spheres were deposited onto a transparent substrate, as shown in Fig. 2, and effort was made to ensure that the spheres exhibited minimal contact with each other. A diffuse light source below the substrate provided a highcontrast image that clearly outlined the edges of the spheres. A calibrated microscope with a magnification of 50x-100x was used to image the spheres. Image analysis software (SPIP 6.6.1 from Image Metrology) was then able to calculate the diameters of the spheres using edge detection and the diameter at the $95^{\text {th }}$ percentile was calculated. The distribution measured for $75 \mu \mathrm{m}$ glass spheres is shown in Fig. 3 below.

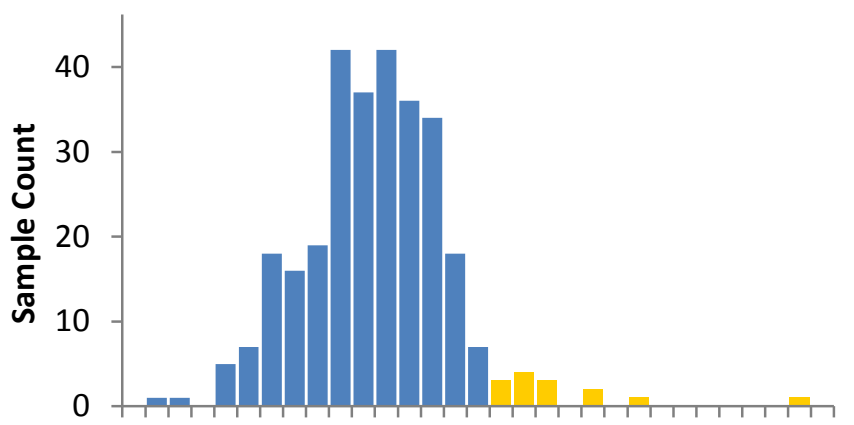

727374757677787980818283848586 Glass Sphere Diameter $(\mu \mathrm{m})$

Fig. 3 Distribution of $75 \mu \mathrm{m}$ glass sphere diameters

The diameter at the $95^{\text {th }}$ percentile was found to be $78.7 \mu \mathrm{m}$. A summary of each measured glass sphere diameter at the $95^{\text {th }}$ percentile is listed in Table 1 . The $95^{\text {th }}$ percentile was used as an approximation of the distance between the platens. Theoretically the platens will be supported by the three largest glass beads in the distribution. At $139 \mathrm{kPa}$ nominal pressure, we do not expect plastic deformation of the nickel surface plating. However, the intrinsic roughness of each side of the platen will affect the thickness measurement.

Table 1. Comparison of nominal sphere diameter reported by the manufacturer with measured sphere diameter from optical microscopy and image processing.

\begin{tabular}{ccc}
\hline $\begin{array}{c}\text { Nominal Sphere } \\
\text { Diameter }(\boldsymbol{\mu m})\end{array}$ & $\begin{array}{c}\text { Mean Sphere } \\
\text { Diameter }(\boldsymbol{\mu m})\end{array}$ & $\begin{array}{c}\mathbf{9 5}^{\text {th }} \text { Percentile } \\
\text { Diameter }(\boldsymbol{\mu m})\end{array}$ \\
\hline $23-27$ & 25.5 & 29.0 \\
$47-50$ & 50.5 & 52.0 \\
75 & 76.5 & 78.5 \\
$123-127$ & 123.5 & 125.5 \\
150 & 152.5 & 158.0 \\
$190-197$ & 193.0 & 196.0 \\
250 & 257.0 & 266.0 \\
\hline
\end{tabular}

\section{BLT Measurement}

The thickness of the various grease layers were controlled by applying glass beads to the grease prior to compressing the meter blocks, however, high magnification images were also taken of the face of the metering blocks to directly measure BLT. Glass spheres of $50 \mu \mathrm{m}$ in diameter were affixed to the sides of the metering blocks to provide unique fiducial markings that allow for the precise measurement of the vertical displacement between the upper and lower metering blocks during the thermal testing. This was completed with a dry contact between the metering blocks and for each grease at every sphere diameter. The side of the metering block at progressively increasing zoom levels is shown in Fig. 4. A high-contrast coloring scheme is used by the image analysis software to detect the similar peaks in brightness on the selected glass sphere.

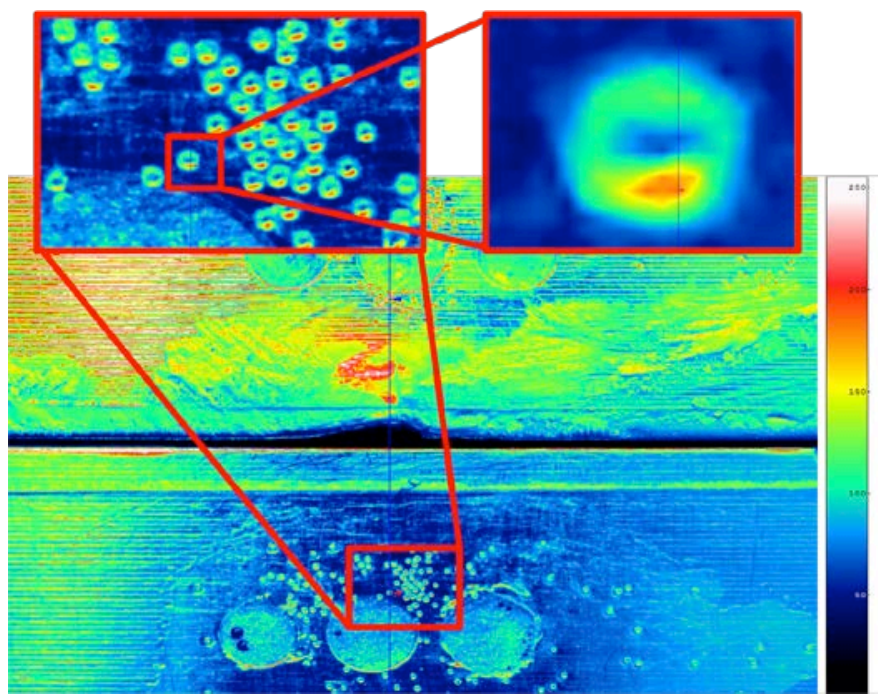

Fig. 4 Glass sphere markings of the face of the metering blocks

A summary of the linear relationship between BLT measurements and glass sphere diameters is shown in Fig. 5.

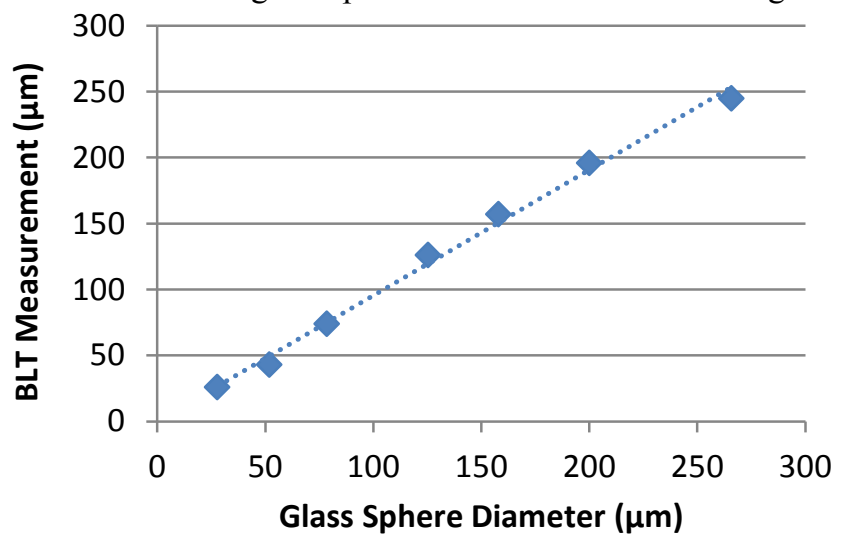

Fig. 5 BLT measurements as a function of glass sphere diameters $\left(95^{\text {th }}\right.$ percentile)

\section{RTD Calibration}

RTDs used for temperature measurement in the upper and lower metering blocks were calibrated to a reference RTD in a bath at every 10 degrees, from $20^{\circ} \mathrm{C}$ to $120^{\circ} \mathrm{C}$. While this ensures temperature homogeneity between RTD 
measurements in a uniform environment, it has been found that a simple calibration is not sufficient when the RTDs are inserted into the machined holes within the metering blocks. This is attributed to variations in the measurement length at the tip of the RTD from manufacturing variations, and the radial variation in temperature from the center of the metering block to the exterior. This variation among RTDs after calibration is shown in Fig. 6, where four RTDs are interchanged into the four measurement holes. To provide the most reliable results, a large set of RTDs was first calibrated, and the RTDs that most closely matched with each other were selected for use in the thermal resistance tester. This calibration procedure ensured that the variation in temperature of the meter blocks was less than $0.05^{\circ} \mathrm{C}$.

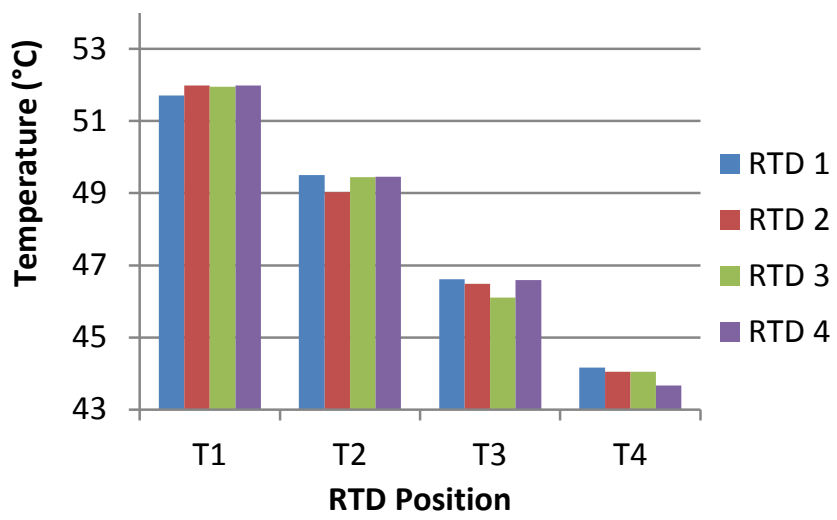

Fig. 6 RTD measurement variation

\section{Large-Area Fixture}

In addition to thermal characterization, the TIMs were evaluated for their ability to withstand pump-out and decomposition during thermal cycling from $-40^{\circ} \mathrm{C}$ to $125^{\circ} \mathrm{C}$. A large-area fixture, shown in Fig. 7, was designed to replicate the interface between a power module baseplate and a cold plate.

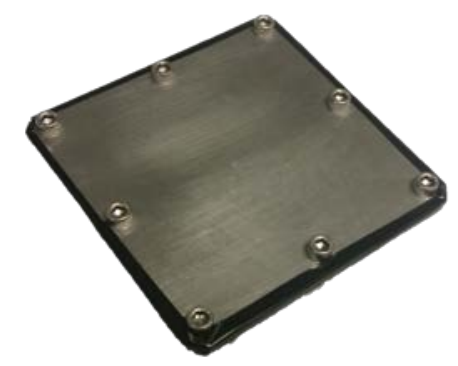

Fig. 7 Large-area fixture $(9 \mathrm{~cm} \times 9 \mathrm{~cm})$ for thermal cycling experiments. The grease is applied with a $2.5 \mathrm{~cm} \times 2.5 \mathrm{~cm}$ stencil in the exact center of the fixture.

Greases were applied using a precisely centered stencil (2.5 $\mathrm{cm} \times 2.5 \mathrm{~cm})$ and then sandwiched between flat invar and aluminum plates. The materials were selected for their dissimilar coefficients of thermal expansion to create periodic mechanical stresses during thermal cycling to accentuate the pump-out of grease from the bond line. Precision ground washers were placed between the coupons to maintain the BLT and bolts secured the fixture together. During accelerated tests, the fixtures were oriented in a vertical position to maximize the effect from gravity. Tape was applied to the edge of the fixtures during acoustic imaging, as the technique requires the sample to be immersed in water to provide a conduit for high-frequency acoustic signals. Xenon flash measurements of thermal diffusivity through the intact fixture provided information on changes in thermal performance of the greases over time. After completion of the tests, the fixtures were dissembled for a compositional analysis on the coupon surfaces.

\section{RESULTS AND DISCUSSION}

\section{Thermal Analysis}

Steady-state measurements were completed for the five greases selected for evaluation. The thermal resistance measurements and linear regressions of each dataset are plotted as a function of BLT in Fig. 8.

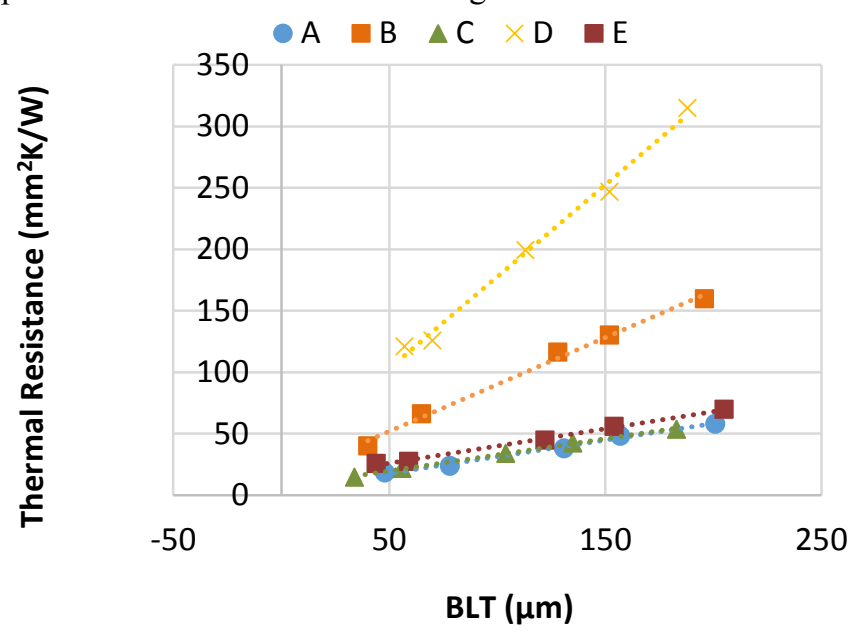

Fig. 8 Thermal resistances of greases as a function of BLT

Greases A, C, and E exhibited similar thermal performance, while greases $\mathrm{B}$ and $\mathrm{D}$ were found to have higher thermal resistances across all BLTs. Each set of sample measurements conform to the linear regression equation:

$$
y=a \cdot x+b
$$

where the constants and the coefficient of determination for each grease are compiled in Table 2.

Table 2. Linear regression constants and coefficient of determination

\begin{tabular}{cccc}
\hline Grease & $\mathbf{a}$ & $\mathbf{b}$ & $\mathbf{R}^{\mathbf{2}}$ \\
\hline A & 0.270 & 4.201 & 0.992 \\
B & 0.761 & 14.078 & 0.993 \\
C & 0.262 & 6.588 & 0.998 \\
D & 1.494 & 28.345 & 0.991 \\
E & 0.280 & 12.185 & 0.996 \\
\hline
\end{tabular}

The thermal conductivity of the sample was obtained from the inverse of the slope, while the contact resistance was determined from the $y$-intercept. The contact resistance value represents the thermal resistance between a grease and both the top and bottom meter blocks. These values are summarized in Table 3. 
Table 3. Bulk thermal conductivity and contact resistances

\begin{tabular}{ccc}
\hline Grease & $\begin{array}{c}\text { Thermal } \\
\text { Conductivity } \\
\text { (W/m-K) }\end{array}$ & $\begin{array}{c}\text { Contact Resistance } \\
\left(\mathbf{m m}^{\mathbf{2}} \mathbf{K} / \mathbf{W}\right)\end{array}$ \\
\hline A & 3.7 & 4.2 \\
B & 1.3 & 14.1 \\
C & 3.8 & 6.6 \\
D & 0.7 & 28.3 \\
E & 3.6 & 12.2 \\
\hline
\end{tabular}

For maximum performance, grease materials must be designed for both high conductivity and compliance with interface surfaces. Initial thermal performance must also be balanced with long-term reliability.

\section{Reliability Analysis}

Steady-state tests indicate the initial thermal performance, but accelerated thermal cycling is necessary to learn how the grease performance changes with time. A major concern is the ability to maintain full contact between surfaces of the platens. Any spreading or voiding of grease at an interface within an electronics package would cause higher operating temperatures for devices and potentially reduce their lifetimes before failures occur or maintenance is required. Acoustic images showing the bond pad shape and sizes of the greases prior to accelerated testing are shown in Fig. 9.

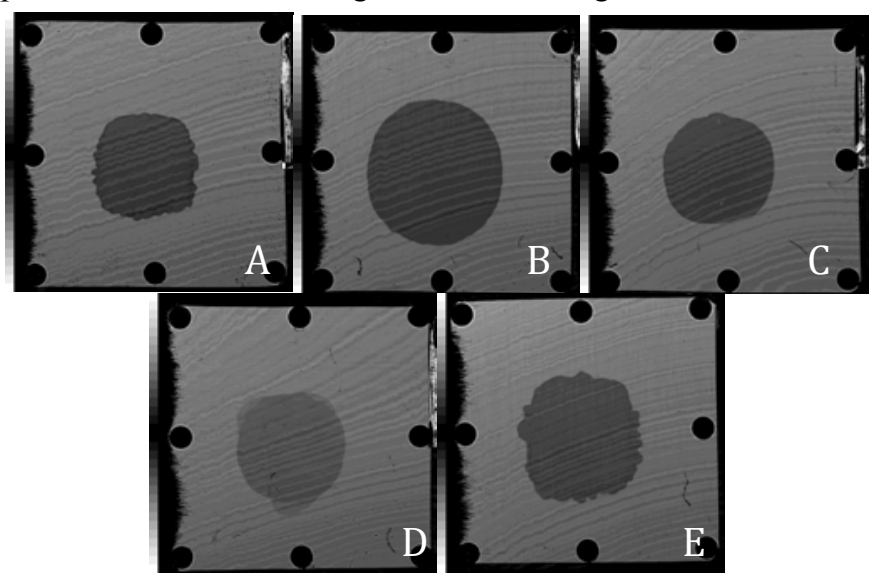

Fig. 9 Acoustic images of greases prior to thermal cycling

The fixtures were cycled from $-40^{\circ} \mathrm{C}$ to $125^{\circ} \mathrm{C}$ and imaged every 10 cycles. After 30 cycles, as seen in Fig. 10, degradation of the contact area of the greases was apparent. The movement and shape of sample B showed considerable change compared to its initial form. Voiding was observed in samples A, C, and E due to separation of the greases into their constituents.

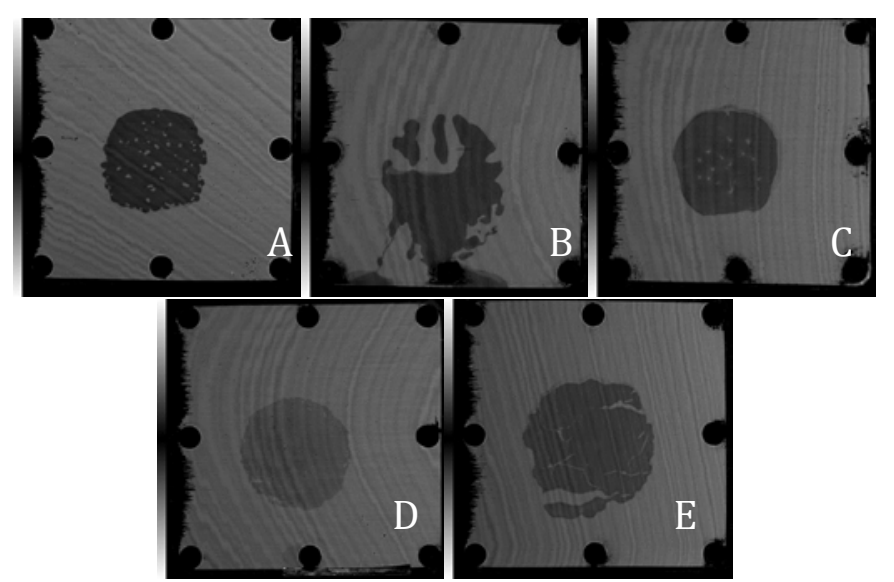

Fig. 10 Acoustic images of greases after 30 cycles

Thermal cycling continued until samples reached 100 cycles. Acoustic images of samples at this progression are shown in Fig. 11 .

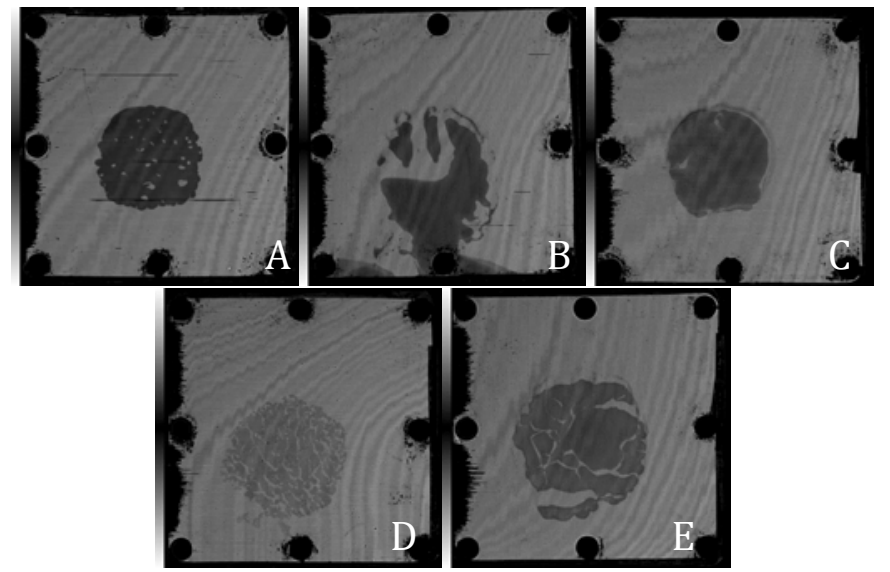

Fig. 11 Acoustic images of greases after 100 cycles

Additional voiding and movement of the samples was observed, but the grease pad shape and sizes largely stabilized between 30 and 100 cycles. Further compositional analysis of the greases will be completed after disassembly of the largeare fixtures.

\section{CONCLUSION}

The ASTM D5470 steady-state measurement technique requires attention to detail in minimizing several sources of error. This paper has outlined best practices followed by other authors and at NREL to continually refine the technique and allow for reproducibility in measurements between different test apparatuses. Care must be taken in the use of glass spheres for thickness spacing, and BLT measurements are equally as important as calibrated RTDs. Several silicone and non-silicone greases were compared and a large-area pump out procedure was also developed. Rigorous testing of TIMs will allow for educated selection of materials for a variety of electronics package designs where managing heat is a primary concern. 


\section{REFERENCES}

[1] R. Prasher, "Thermal Interface Materials: Historical Perspective, Status and Future Directions," in Proceedings of the IEEE, vol. 94, no. 8, pp. 1571-1586, 2006.

[2] M. Cummings, N. Shephard, K. Su, and D. Bhagwagar, "Efficient Method for Characterization of Various Thermal Interface Materials," 2010 12th IEEE Intersociety Conference on Thermal and Thermomechanical Phenomena in Electronic Systems, Las Vegas, NV, 2010, pp. 1-6.

[3] ASTM Standard D5470-12, Standard Test Method for Thermal Transmission Properties of Thermally Conductive Electrical Insulation Materials, West Conshohocken, PA: ASTM International, 2012, DOI: 10.1520/D5470-12.

[4] S. Narumanchi, M. Mihalic, K. Kelly, and G. Eesley, 2008, "Thermal Interface Materials for Power Electronics Applications," Proceedings of the ITHERM Conference, Orlando, FL, pp. 395-404, 2008.

[5] D. DeVoto, P. Paret, M. Mihalic, S. Narumanchi, A. BarCohen, and K. Matin, "Thermal performance and reliability characterization of bonded interface materials (BIMs)," Proceedings of the ITHERM Conference, Orlando, FL, USA, 2014.

[6] E. Cousineau, K. Bennion, D. DeVoto, M. Mihalic, and S. Narumanchi, "Characterization of Contact and Bulk Thermal Resistance of Laminations for Electric Machines," NREL Technical Report, NREL/TP-5400-63887, 2015.

[7] C.J. Lasance, "The urgent need for widely-accepted test methods for thermal interface materials," Semiconductor Thermal Measurement and Management Symposium, 2003. Nineteenth Annual IEEE. pp. 123-128, 2003.

[8] C.I. Chen, C.Y. Ni, C.M. Chang, D.S. Liu, H.Y. Pan, and T.D. Yuan, "Thermal characterization of thermal interface materials," Experimental Techniques, vol. 32, no. 3, pp. 4852, May-Jun, 2008.

[9] A.M. Khounsary, D. Chojnowski, L. Assoufid, and W.M. Worek, "Thermal contact resistance across a copper-silicon interface," Proceedings of SPIE, High Heat Flux and Synchrotron Radiation Beamlines, vol. 3151, pp. 45-51, December, 1997.

[10] J. Culham, P. Teertstra I. Savija, and M.M. Yovanovich, "Design, assembly and commissioning of a test apparatus for characterizing thermal interface materials," ITHERM 2002. The Eighth Intersociety Conference on Thermal and Thermomechanical Phenomena in Electronic Systems. pp. 128-135, 2002.

[11] V. Székely, A. Vass-Varnai, and E. Kollar, "Re-design and validation of the 'STATIM' TIM tester," Thermal Investigations of ICs and Systems (THERMINIC), 2010.

[12] R. Kempers, P. Kolodner, A. Lyons, and A.J. Robinson,"A high-precision apparatus for the characerization of thermal interface materials," Review of Scientific Instruments, vol. 80, p. 095111, 2009.

[13] J. Xu, and T. S. Fisher, "Enhancement of thermal interface materials with carbon nanotube arrays," International Journal of Heat and Mass Transfer, vol. 49, no. 9-10, pp. 1658-1666, May, 2006.

[14] M. AboRas, D. May, R. Schacht, T. Winkler, S. Rzepka, B. Michel, and B. Wunderle, "Limitations and accuracy of steady state technique for thermal characterization of thermal interface materials and substrates," Fourteenth Intersociety Conference on Thermal and Thermomechanical Phenomena in Electronic Systems (ITherm), Orlando, FL, 2014, pp. 12851293. 